a logical manner and the subdivisions of each chapter are clearly titled. When used in conjunction with its excellent index, this well produced volume provides an interesting and useful source of information for all who seek a better understanding of immunological phenomena, and poses many fascinating questions which may stimulate some readers to find the answers.

B. VERNON-ROBERTS

\section{MAN AND INSECTS}

\section{Entomological Parasitology}

The Relations between Entomology and the Medical Sciences. By Marcel Leclercq. Translated by G. Lapage. (International Series of Monographs in Pure and Applied Biology. Division: Modern Trends in Physiological Sciences, Vol. 29.) Pp. xviii +158. (Pergamon Press: Oxford, London and New York, March 1969.) 63s; $\$ 8.00$.

THIs book on medical entomology, by a physician of standing in Belgium, has attempted with considerable success to view the whole field of the subject, yet it retains a fresh approach by focusing predominantly on the personal contacts of man with insects and their like. The more traditional emphasis on disease pathogens, and their vectors, control and prevention, are dealt with in only two of the thirteen chapters. Yet much is given for the reader to assimilate about disease transmission from virus infections, bacterial and rickettsial diseases, malaria, trypanosomiasis, leishmaniasis, to the filarial worms and some other helminths. The complexity of vectorparasite associations in relation to animal reservoirs of human diseases, and infections of domestic stock, is summed in numerous tables, which also indicate geographical distributions. All this is further amplified by cyclical diagrams outlining host-parasite-vector relationships. Three maps outline the world distribution of malaria, yellow fever and tularaemia. Control is discussed at some length in terms of insecticides and repellents, with comment on other approaches and their prospects, more enthusiastically for some than reality would, as yet, concede as practical propositions. The bulk of the book is, however, at the personal level. Most of the thirteen chapters are about stings, bites, blistering and urtications, allergy and reactions, myiasis, scabies and other skin and scalp infestations or irritations, therapeutic uses of insects, edible insects, some aspects of domestic and occupational contacts between man and arthropods, and the use of entomology in law cases. This last theme is elaborated round the author's work on successive populations of different insects and mites frequenting a carcass progressively as it decomposes, and application of this to assessing the time of death in murder cases makes for more gruesome scientific reading than usual. There is a chapter on insect dispersal, naturally and by human transport of all kinds. None of the pests, vectors, or pathogens are illustrated, or deseribed other than by their common names or in elements of zoological classification from time to time. The reader must search elsewhere according to his needs and inclinations. The scientist familiar with the subject must have reservations about some errors of fact he will find, but should appreciate the novelty of presentation and respect the extensive bibliography of more than 700 full references. There is an index to pathogens and vectors, another to authors. By and large, for important topics eitations are well into the early $1960 \mathrm{~s}$, but some have their source, and relevance, much farther back in time. There is likely to be a good deal of fascination in this book for the general reader. Even so, neither scientist nor lay reader is likely to swallow without a pinch or two of salt the concluding generalization on edible insects that "caterpillars and chrysalids of butterflies are eaten almost everywhere". D. S. Bertram

\section{RESISTANCE TO DISEASE}

\section{Disease Resistance in Plants}

By J. E. van der Plank. Pp. $x+206$. (Academic Press: New York and London, October 1968.) $88 s 8 d$.

After an introduction the definitions and concepts used by the author are fully detailed. The term oligogenic as an opposite to polygenic is proposed. The author suggests that the word multigenic should be avoided as multi- is Latin and a barbarous invasion of the Greek prefixes used in genetics. Resistance is characterized as vertical or horizontal throughout the book. The definitions imply that only in vertical resistance is there a differential interaction between host varieties and races of a pathogen. Examples of these interactions are well illustrated. In the same chapter the author proposes definitions of the terms aggressive and virulent. Races vary in aggressiveness when resistance is horizontal and in virulence where it is vertical. Examples of these reactions are fully illustrated and discussed.

The progress of disease in relation to resistance in the host is discussed in chapter three. The author attempts to answer two questions. First, how is resistance translated into a useful effect, and second, how does resistance curb the increase of disease with time? Vertical resistance delays the start of an epidemic, this being the only known beneficial effect of $\mathrm{R}$ genes. They do not reduce infection rate and therefore do not slow down the epidemic after it has started. On the other hand, horizontal resistance slows down the rate of spread of the disease. The mathematical background of these conclusions drawn up from published data is presented in the second half of the chapter.

Vertical resistance in the host and stabilizing selection in the pathogen are considered in chapters four and five. In the rather lengthy fourth chapter, data from a number of papers are presented indicating that where there is only vertical resistance races of a pathogen with the correct level of virulence can survive. When the vertical resistance gene is lacking, virulence to match it is unnecessary and stabilizing selection operates in favour of races of the pathogen without unnecessary virulence. The theory of vertical and horizontal resistance is taken further in chapter six. The author rightly states that it would help practical plant breeding if all the marks of each type of resistance could be recognized and particularly where vertical resistance is likely to be unstable. In the next three chapters the importance of hori\%ontal resistance is considered. As it is the most stable form, the methods of bringing enough of it together $t:$ be effective are discussed. It is certainly not the complete answer and the use of multilines as a substitute or supplement would retain the special advantage of vertical resistance.

In chapter ten the author constructs a simple mathe. matical model to determine the effects of resistance on the spread of disease. This holds a certain fascination but can certainly be avoided by the non-mathematical reader. In the final chapter, evidence is presented suggest ing that the effects of changes in the host, pathogen and environment are equivalent in the disease triangle. with the logical exclusion of environmental effects acting while the pathogen is outside the host. The author's final proposition is that as the genes governing horizontal resistance are simply those occurring ordinarily in healthy plants, which regulate normal processes, some horizontal resistance is always available against specialized pathogens.

The text and illustrations are well presented and there is a bibliography of 126 references. As the author states in the preface, the chapters interlock because resistance theories are becoming consistently integrated. As a whole the book becomes a little repetitive but remains stimulating and conducive to thought.

D. S. KIRKHAM 